\title{
Efficiencies of health insurance business in India: An application of DEA
}

\author{
Dr. Sumninder Kaur Bawa and Miss Ruchita
}

\author{
Department of Commerce and Business Management, \\ Guru Nanak Dev University, Amritsar, Punjab. India
}

\begin{abstract}
In order to measure the efficiency, number of methods have been developed and applied. Out of these the principal methods used are: Data Envelopment Analysis (DEA) and Stochastic Frontier. DEA is a non parametric mathematical programming approach for the measurement of efficiencies and inefficiencies. This paper seeks to use DEA to evaluate the efficiencies of health insurance business of general insurance companies in India. The present study is focused upon 10 general insurance companies of India including 4 public sector companies and cover a period of 8 years from 2002-03 to 2009-10. The study uses the equity capital and labour (including commission, agents' fees, referral and other expenditure) as input and net premium as output. It was observed that overall general insurers carrying health insurance business at an average technical efficiency of $73 \%$, pure technical efficiency of $92 \%$ and scale efficiency of $78 \%$. On the other hand sector wise performance analysis has indicated that technical efficiency of all the private sector companies is $77 \%$, which is $10 \%$ more than that of public sector Companies. This can be attributable to the fact that private sector companies are operating on increasing return to scale and taking the advantages of pure technical efficiency and scale efficiency.
\end{abstract}

Keywords: Efficiencies, Frontier, Data Envelopment Analysis.

\section{INTRODUCTION}

In order to measure the efficiency, number of methods have been developed and applied. Out of these the principal methods used are: Data Envelopment Analysis and Stochastic Frontier. Data Envelopment Analysis (DEA) is a non parametric mathematical programming approach to frontier estimation, which uses data to determine a sphere which represent the best practice for measuring efficiencies and inefficiencies. Measurement of efficiencies using DEA involves the two concepts: traditional concept and modern concept. The traditional concept cannot work with multi-input, whereas the modern efficiency concept can work effectively and efficiently with multi-input. Modern efficiency measurement concept to DEA is contributed with Farrell (1957), who paid attention towards the work done by Debreu (1951) and defined the measurement of efficiency that can work with multi-input. Thereafter the enhancement to modern concept of efficiency was made in term of simple measure of firm efficiency that can work with multiinput as well as multi-output. The credit for the enhancement to the modern concept of efficiency goes to A. Charnes, W.W. Cooper and E. Rhodes, who introduced for the first time in 1978 the first model of DEA known as $C^{2} R$ model, which can work simultaneously with multi-inputs and multi-output. Since its conception it was utilized in many areas to identify and analyze the efficiencies due to its peculiar feature of ability to work with both multiinputs and multi-output.

The Data Envelopment Analysis has number of favorable economic implications because it is fit to evaluate the productive efficiency of different lines of business and the identification of production function. Besides this, its scope is far broader than imagination because of its wide range of applicability in various fields such as hospitals, banks, insurance companies, air force wings, universities, cities, courts, business firms, and others, including the performance of countries, regions, states etc.

In the insurance area, both the national and international markets are becoming competitive as consequences of liberalization and privatization policies adopted by various countries. Insurance markets worldwide continue to undertake procompetitive reform predicated on the expectations that competitive markets are in a better position to enhance consumers' choice and welfare than are rigidly regulated insurance markets. As a consequence, dozens of countries have deregulated or liberalized their insurance markets. One of such liberalized insurance market is the Indian insurance 
market, where twenty six percents Foreign Direct Investments (FDIs) is allowed in insurance sector. Forwarding attention deep towards Indian Insurance market will reflect that since its inception it has faced number of milestone in the phases of development. But inspite of those milestones the Indian insurance industry found the new track of success and growth in the year 1999, when reforms in the insurance sector was initiated with lying and passing of IRDA Bill in Parliament. The Insurance Regulatory and Development Authority (IRDA), since its incorporation in April, 2000 have fastidiously stuck to its schedule of framing regulations and opening up the insurance sector to private players as well as permitting FDIs in insurance sector. The FDI was allowed on the same line of as other countries are considering that privatization and liberalization will ensure the efficient and effective services to the insured ones. To what extent Indian liberalized and privatized market has achieved its objectives of increasing and enhancing efficiency of insurers as well as enhancement of consumers' choice and welfare is a matter of great controversy and discussion.

Various studies related directly or indirectly to the objectives of the present study have been reviewed. Houston and Simon (1970) have examined the relation between average costs and premium receipts of life insurance companies of U.S and concluded that average costs are constant beyond $\$ 100$ million of premiums. Charnes, Cooper and Rhodes (1978) provided with a nonlinear programming model which have given a new definition of efficiency. This model can objectively determine the weights with reference to observational data for multi-input and multi-output. Praetz (1980) has explored the average cost relationship between life insurers and each of ten insurer characteristics. The data used are drawn from 90 insurers with more than half the life insurance in force with U.S. insurers. The study reveals that the following independent variables are significant in producing economies of scale, premium income, new business ratio, proportion of whole life business, and size of insurer (i.e., giant mutual insurers). Doherty (1981) analyzed the conceptual and econometric problems arising from the use of premium income as a proxy for output and suggested that it leads to serious problems of simultaneous equation bias and errors in variables. Therefore a delivery-based output measure is theoretically superior and will encounter less severe econometric problems. Sherman (1981) investigated the application of DEA to an artificial data set reflecting the operations of a hospital department and provided that the widely used single- output measures applied to this data set is found to be less reliable in this multiple output environment. Weiss (1986) concluded that applicability of the output and productivity measurement methodologies developed is not limited to the specific insurers studied, but rather can be used as a guide in measuring the productivity of any life insurer or insurance industry. Grace and Timme (1992) analyzed the U.S. life insurance industry and provided the estimation of both the overall and product specific scale economies, as well as, pairwise cost complementarities for a wide variety of products. In contrast, previous studies only provide a single point estimate of industry cost characteristics using the sample mean output vector. This study, therefore, provides a more complete representation of the industry's cost characteristic. Cummins, Turchetti and Weiss (1996) examined efficiency and productivity under the new European regulatory regime and indicated that technical efficiency in the Italian insurance industry ranged from 70 to 78 percent during the sample period. However, productivity declined significantly over the sample period, with a cumulative decline of about 25 percent. Cummins and $\mathrm{Zi}$ (1998) provided that alternative methodologies give significantly different estimates of efficiency for the insurers. Moreover the efficiency rankings are quite well-preserved among the econometric methodologies; but the rank correlations are lower between the econometric and mathematical programming categories and between alternative mathematical programming methodologies. Korhonen (1997) recommended the use of Pareto Race (Korhonen and Wallenius [1988]) for purpose to make a free search on the efficient frontier due to the reasons that it may simply control the search with some function keys; the information is displayed as bar graphs and in numeric form; the search can be terminated at any time. Fukuyama (1997) investigated the productive efficiency and productive changes of Japanese life insurance companies and reveals mutual and stock companies possess identical technologies, but the productive efficiency and productive performance changes from time to time in the case of stock and mutual under different economic conditions. Brockett, cooper, Golden, Rousseau and Wang (1998) examined the efficiency effects of different forms of ownership (stock versus mutual) and types of marketing system (agency versus direct) for the US property-liability insurance industry and provided that the use of (nonparametric) rank-order statistics then produce results which differ from these other studies. Cummins and 
Misas (2001) analyzed the causes and effects of consolidation in Spanish insurance industry and showed that many small, inefficient, and financially under-performing firms were eliminated from the market due to insolvency or liquidation and those acquirers in the mergers and acquisitions market prefer relatively efficient target firms. Boonyasai, Grace and Skipper (2002) examined the impact of liberalization and deregulation of four life insurance markets and found that liberalization and deregulation of the Korean and Philippine life insurance industries seem to have stimulated increases and improvements in productivity whereas liberalization of the Taiwanese and Thai life insurance industries seems to have had little effect on increases and improvements in productivity. Cummins, Weiss and $\mathrm{Zi}$ (2003) provided the evidence for the existence of weak economies of scope in the U.S. insurance industry and also that strategic focus appears to be a better strategy. Martin (2003) evaluated the performance of Zaragoza University's Departments (Spain) through the comparison of a group of decisions units. The result of the study reveals those departments who carry out their activities efficiently. Chang (2006) concluded that both return on assets and sign of profitability influence a heavier financial ratio as well as operating index on performance. Bikker and Leuvensteijn (2008) have examined the competitive nature of Dutch life insurance industry and provided that limited competition in Dutch life insurance industry as compared to Netherlands. Eling and Luhnen (2008) analyzed and provided new empirical evidence on frontier efficiency measurement in the insurance industry and found that a steady technical and cost efficiency growth in international insurance markets from 2002 to 2006, with large differences across countries. Yuan and Phillips (2008) examined the efficiency effect from the possible economies of scope across two formally separate sectors by estimating multi-product costs, revenue, and profit function and suggested that a significant number of cost scope diseconomies, revenue scope economies, and weak profit scope economies exist in the postGLB U.S. integrated banking and insurance sectors. Eling and Luhnen (2010) provided an overview on frontier efficiency measurement in the insurance industry and shown that there is a broad consensus with regard to the choice of methodology and input factors, the difference lies in case of in output measurement. Owusu, Dontwi, Seidu, Abudulai, and Sebil (2010) evaluated the performance or efficiency Ghanaian general insurance companies from the year 2002 to 2007 and provided with the result that Ghanaian general insurers operated at an average overall efficiency of $68 \%$, technical efficiency of $87 \%$ and scale efficiency of $78 \%$.

Having the in-depth review of related studies has provided that there is a huge importance of DEA in evaluating the performance and efficiency of the insurance industry. Keeping in to mind such an importance of DEA model in evaluation of an entity, we have used the same in the present study in order to achieve the following objectives:

- To evaluate the efficiencies of health insurance business of general insurance companies.

- To determine the improvement space and improvement direction in order to render the inefficient company to be efficient.

Data Base and DEA Methodology: The present study is covering a period of 8 years from 2002-03 to 2009-2010. The base year is taken as 2002 i.e. the companies which are providing health insurance since 2002 are forming a part of the study. The basic reason behind the selection of base year as 2002 lies in the fact that, this is the exclusive year in which maximum numbers of general insurance companies are operating in insurance industry and started extension of health insurance under their existing network of service. The companies under the scope of study include, Tata AIG General Insurance Company Limited, IFFCO Tokio General Insurance Company Limited, Reliance General Insurance Company Limited, Royal Sundram Alliance Insurance Company Limited, Bajaj Allianz General Insurance Company Limited, ICICI Lombard General Insurance Company Limited, United India Insurance company limited, Oriental Insurance Company Limited, New India Assurance Company Limited and National Insurance Company Limited. The study is entirely based upon secondary data, which is mainly drawn from the annual reports of the insurance companies under consideration. Beside this the use of statistical year book of IRDA and other publication related with the insurance was made for the collection of certain facts and figures necessary for the present study.

In order to accomplish the objectives of study, we used the Data Envelopment Analysis (DEA), a mathematical programming approach which estimates the frontier by solving a series of linear programming problems. The efficiency of the each firm is measured with respect to distance from the frontier. Efficiency score ranges from 0 to 1 and firm 
having efficiency score equal to 1 referred as fully efficient firm or the firm operating on the frontier and the firm having efficiency score less than 1 referred as inefficient firm or the firm operating away from the frontier. DMUs efficiency is obtained by solving a set of linear programming problems which can be categorized in to following according to treatment of slack:

One-stage DEA which uses the following equation and calculate slack residually:

$$
\begin{array}{r}
\min _{\theta \lambda} \theta_{s} \\
s t-y_{i}+Y \lambda \geq 0, \\
\theta_{X i}-X \lambda \geq 0, \\
\lambda \geq 0
\end{array}
$$

Where $\theta$ is a scalar and $\lambda$ is a $N \times 1$ vector of constants. This envelopment form involves fewer constraints than the multiplier form $(\mathrm{K}+\mathrm{M}<\mathrm{N}+1)$, and hence is generally preferred to solve. The value $\theta$ obtained will be the efficiency score for the i-th DMU. It will satisfy $\theta \leq 1$, with a value of 1 indicating a point on the frontier and hence a technical efficient DMU, according to Farrell (1957) definition. Moreover the linear programming problem must be solved $\mathrm{N}$ times, once for each DMU in the sample.

Two-stage DEA which uses the following equation:

$$
\begin{gathered}
\min _{\lambda \mathrm{OS}, I S}-\left(M 1^{\prime} O S+\mathrm{K} 1^{\prime} \mathrm{IS}\right), \\
\text { St } \quad-y_{i}+Y \lambda-O S=0, \\
\theta_{X i}-\mathrm{X} \lambda-\mathrm{IS}=0, \\
\lambda \geq 0, O S \geq 0, \text { IS } \geq 0, \ldots \ldots \ldots \ldots \ldots
\end{gathered}
$$

Where OS is an Mx1 vector of output slack, IS is a $\mathrm{K} x 1$ vector of input slacks and $\mathrm{M} 1$ and $\mathrm{K} 1$ are $\mathrm{Mx} 1$ and $K x 1$ vector of ones, respectively. In this case, $\theta$ is not variable rather its value is taken from the first stage results. Moreover it is required to be solved for the each of the N DMU's involved. However there are two problems associated with this: firstly, sum of slack maximized rather than minimized. Secondly, it is not invariant to units of measurement. The alternative to get rid of these problems is the use of multi-stage DEA.
Multi-stage DEA, where we conduct a sequence of radial LP's to indentify the efficient projected point. This method is computationally more demanding than the other two methods above specified due to the fact that it identifies efficient projected points which have input and output mixes which are as similar as possible to those of the inefficient points, and that it is also invariant to units of measurement. Hence we have used multi-stage method over the other two alternatives.

(Source: Coehli, T.J. 1996)

The above stated equations are used in DEA to evaluate the efficiencies of the DMUs. In our paper efficiency is defined as technical efficiency. Further only the measurement of technical efficiency is not enough, so we worked ahead and measured the technical efficiency both with Constant Return to Scale (CRS) as well as with Variable Return to Scale (VRS). The technical efficiency which is measured with VRS is also known as Pure Technical Efficiency. Besides this, scale efficiency has also been calculated for all the firms during the period under consideration.

Technical Efficiency: Technical efficiency can be regarded as the product of pure technical efficiency and scale efficiency. It reflect the ability of the firm to obtain the maximum output from a given set of input or the efficiency with which inputs are transformed into output or just the output/input ratio.

Pure Technical Efficiency: In pure technical efficiency, production line with variable return to scale is used. From the view point of economics, this will release the restrictions of scale. Therefore, the inefficiency only lies in the factors such as productivity, resource allocation and management.

Scale Efficiency: In contrary to the case of pure technical efficiency, only the factor of scale is effective here, while the factors of productivity, resource allocation and management are excluded.

(Source: Qiu and Chen 2006)

http://www.ccfr.org.cn/cicf2006/cicf2006paper/20060 130033345.pdf

Measurement of Inputs and Outputs: The result of the DEA depends heavily upon the variable of the input and output specified. Therefore for the success of the study an accurate selection of the variable of input and output is necessary. By the study of literature it came into notice that researchers have general agreement on the selection of input's 
indicators. Generally labor, capital and materials are selected as shown in Grace and Timme (1992), Gardner and Grace (1993), Cummins and Zi (1998).

The variables of inputs which are considered under the present study are as:

Equity Capital (X1): According to the theory of corporate finance, financial capital can be authorized capital or invested capital. The invested capital includes long term debt and equity capital. However, reserve constitutes almost all the long term debt of insurers. Debt which constitutes the part of the invested capital does not remain same. Therefore, we cannot say that insurers use this long term debt to support their business. So in this study, we have taken equity share capital as the first indicator of input.

Amount of Labor (X2): As the insurance companies do not constitute the part of the manufacturing industries rather form a part of the financial service industry, so it does not uses raw material as primary input. In financial service industry the cost of labor is the most important input. The main difficulty regarding this input was to get salary data of insurers, which is not feasible. So alternatively we have taken amount of commission, agents' fees, referral and other expenditure as the second indicator of input.

The variables of outputs which are considered under the present study are as: As far as the variable of output is concerned wide diversity found in literature, because of the fact that defining and measuring outputs in the insurance industry is a challenging task. In various studies three commonly used outputs are: premium income, weighted sum of activities, and incurred benefits plus additions -toreserves. In most of the previous studies net written premiums or net earned premiums have been used as proxies for outputs. Doherty (1981); Yuengert (1993); Cummins and $\mathrm{Zi}$ (1998) thinks premium cannot reflect the quantity of output. However, Houston and Simon (1970) thinks premium to insurers is what income to manufacturers, and therefore can be regarded as the indicator of output. Similar arguments appeared in: Praetz (1980); Fields and Murphy (1989); Grace and Timme (1992); Gardner and Grace (1993); Rai (1996); Diacon (2001); and Li (2005). They consider premium as an appropriate indicator of output, assuming the product is homogeneous and competitive pressures compel all insurers to charge the same price.
Finally we have selected two indicator of input as equity capital and labour (including commission, agents' fee, referral and other expenditure); and one indicator of output as net premium, which is also in accordance with the assumption of DEA, that number of Decisions Making Units should be three time of number of inputs and outputs.

Empirical Results, its Analysis and Interpretation I. Analysis on Technical Efficiency, Pure Technical Efficiency and Scale Efficiency: The analysis of TE, PTE and SE of health insures has done by two ways: A. Company wise analysis; B. Year wise analysis.

A. Company wise analysis: This has been done to arrive at conclusive findings of TE, PTE and SE of health insurance business of general insurance companies in India during the period under consideration. In other words the effort has been made to find out individually which of the company lie on the frontier and which are away from the frontier.

Table 1 has shown that New India Assurance Company Limited and National Insurance Company Limited are the two fully efficient companies during 6 out of 8 years of period under consideration. Their efficiency remain static up to 2007-08 or 2008-09 thereafter its efficiency score shows decreasing trend which might be attributable to the fact that they have achieved the level of maturity and due to competition their position is gradually acquired by private sector insurance company. On the other hand the study found the three inefficient companies; two are from the private sector and one is from the public sector which does not lie on the frontier in any year. Tata AIG and Royal Sundram out of private sector and United India out of public sector is inefficient companies as their efficiency score were not equal to 1 in any year. But if compare these three inefficient companies will provide insight that although the private sector company Tata AIG, Royal Sundram does not lie on the frontier, yet its efficiency scores improved over a period of time, which is not in the case of United India Insurance Company which shows reverse trend during the period under consideration. This shows that public sector companies are gradually underperforming and their position is slowly and steadily taken over by the private sector companies with regard to health insurance. This can be regarded as good sign because it reflects the increasing competition in the market, which will enhance product choice for consumers with efficient quality of services. 
Table 1 shows the company wise analysis of TE, PTE and SE

\begin{tabular}{|c|c|c|c|c|c|c|c|c|}
\hline \multicolumn{3}{|c|}{ Tata AIG General Insurance Company Lim } & $\begin{array}{l}\text { nited } \\
2004-05\end{array}$ & 2005-06 & 2006-07 & 2007-08 & $2008-09$ & $2009-10$ \\
\hline TE & 0.041 & 0.057 & 0.046 & 0.079 & 0.445 & 0.413 & 0.849 & 0.728 \\
\hline PTE & 0.980 & 0.89 & 0.810 & 0.552 & 0.963 & 1.000 & 1.000 & 1.000 \\
\hline SE & 0.042 & 0.063 & 0.057 & 0.151 & 0.462 & 0.413 & 0.849 & 0.728 \\
\hline RtoS & Increasing & Increasing & Increasing & Increasing & Increasing & Increasing & Increasing & Increasing \\
\hline \multicolumn{9}{|c|}{ IFFCO Tokio General Insurance Company Limited } \\
\hline Indicators & 2002-03 & 2003-04 & 2004-05 & 2005-06 & 2006-07 & 2007-08 & 2008-09 & 2009-10 \\
\hline TE & 0.198 & 0.137 & 0.161 & 0.134 & 0.676 & 0.247 & 0.513 & 1.000 \\
\hline PTE & 1.000 & 1.000 & 1.000 & 0.475 & 1.000 & 0.517 & 0.867 & 1.000 \\
\hline SE & 0.198 & 0.137 & 0.161 & 0.281 & 0.676 & 0.478 & 0.592 & 1.000 \\
\hline RtoS & Increasing & Increasing & Increasing & Increasing & Increasing & Increasing & Increasing & Constant \\
\hline \multicolumn{9}{|c|}{ Reliance General Insurance Company Limited } \\
\hline Indicators & 2002-03 & 2003-04 & 2004-05 & 2005-06 & 2006-07 & 2007-08 & 2008-09 & 2009-10 \\
\hline TE & 0.029 & 0.300 & 0.283 & 0.241 & 0.567 & 0.617 & 1.000 & 1.000 \\
\hline PTE & 0.980 & 1.000 & 1.000 & 1.000 & 1.000 & 1.000 & 1.000 & 1.000 \\
\hline SE & 0.030 & 0.300 & 0.283 & 0.241 & 0.567 & 0.617 & 1.000 & 1.000 \\
\hline RtoS & Increasing & Increasing & Increasing & Increasing & Increasing & Increasing & Constant & Constant \\
\hline \multicolumn{9}{|c|}{ Royal Sundram Alliance General Insurance Company Limited } \\
\hline Indicators & $2002-03$ & 2003-04 & 2004-05 & 2005-06 & 2006-07 & 2007-08 & 2008-09 & 2009-10 \\
\hline TE & 0.033 & 0.167 & 0.124 & 0.205 & 0.352 & 0.275 & 0.450 & 0.413 \\
\hline PTE & 0.866 & 0.784 & 0.782 & 0.746 & 0.734 & 0.647 & 0.926 & 0.612 \\
\hline SE & 0.038 & 0.213 & 0.159 & 0.275 & 0.480 & 0.425 & 0.486 & 0.675 \\
\hline RtoS & Increasing & Increasing & Increasing & Increasing & Increasing & Increasing & Increasing & Increasing \\
\hline \multicolumn{9}{|c|}{ Bajaj Allianz General Insurance Company Limited } \\
\hline Indicators & 2002-03 & 2003-04 & 2004-05 & 2005-06 & 2006-07 & 2007-08 & 2008-09 & $2009-10$ \\
\hline TE & 0.032 & 0.258 & 0.191 & 0.244 & 1.000 & 1.000 & 0.775 & 0.702 \\
\hline PTE & 0.914 & 0.928 & 0.932 & 0.965 & 1.000 & 1.000 & 1.000 & 0.751 \\
\hline SE & 0.035 & 0.278 & 0.205 & 0.253 & 1.000 & 1.000 & 0.775 & 0.934 \\
\hline RtoS & Increasing & Increasing & Increasing & Increasing & Constant & Constant & Increasing & Decreasing \\
\hline \multicolumn{9}{|c|}{ ICICI Lombard General Insurance Company Limited } \\
\hline Indicators & $2002-03$ & 2003-04 & 2004-05 & $2005-06$ & 2006-07 & 2007-08 & 2008-09 & 2009-10 \\
\hline TE & 0.041 & 1.000 & 0.332 & 0.246 & 0.492 & 0.255 & 0.631 & 0.814 \\
\hline PTE & 0.912 & 1.000 & 0.492 & 0.502 & 0.501 & 0.323 & 0.847 & 1.000 \\
\hline SE & 0.045 & 1.000 & 0.674 & 0.491 & 0.982 & 0.788 & 0.744 & 0.814 \\
\hline RtoS & Increasing & Constant & Increasing & Increasing & Decreasing & Increasing & Decreasing & Decreasing \\
\hline \multicolumn{9}{|c|}{ United India Insurance Company Limited } \\
\hline Indicators & $2002-03$ & 2003-04 & 2004-05 & 2005-06 & 2006-07 & 2007-08 & 2008-09 & 2009-10 \\
\hline TE & 0.939 & 0.635 & 0.735 & 0.811 & 0.676 & 0.061 & 0.755 & 0.563 \\
\hline PTE & 1.000 & 1.000 & 1.000 & 1.000 & 0.777 & 0.667 & 0.796 & 0.912 \\
\hline SE & 0.939 & 0.635 & 0.735 & 0.811 & 0.870 & 0.092 & 0.948 & 0.618 \\
\hline RtoS & Increasing & Increasing & Increasing & Increasing & Increasing & Increasing & Decreasing & Decreasing \\
\hline \multicolumn{9}{|c|}{ Oriental Insurance Company Limited } \\
\hline Indicators & 2002-03 & 2003-04 & 2004-05 & 2005-06 & 2006-07 & 2007-08 & 2008-09 & $2009-10$ \\
\hline TE & 0.595 & 0.550 & 0.728 & 0.872 & 0.988 & 0.835 & 1.000 & 0.711 \\
\hline PTE & 1.000 & 1.000 & 1.000 & 1.000 & 1.000 & 1.000 & 1.000 & 1.000 \\
\hline SE & 0.595 & 0.550 & 0.735 & 0.872 & 0.988 & 0.835 & 1.000 & 0.711 \\
\hline RtoS & Increasing & Increasing & Increasing & Increasing & Increasing & Increasing & Constant & Decreasing \\
\hline \multicolumn{9}{|c|}{ New India Assurance Company Limited } \\
\hline Indicators & $2002-03$ & 2003-04 & 2004-05 & $2005-06$ & 2006-07 & 2007-08 & 2008-09 & $2009-10$ \\
\hline TE & 1.000 & 1.000 & 1.000 & 1.000 & 1.000 & 1.000 & 0.843 & 0.587 \\
\hline PTE & 1.000 & 1.000 & 1.000 & 1.000 & 1.000 & 1.000 & 1.000 & 1.000 \\
\hline SE & 1.000 & 1.000 & 1.000 & 1.000 & 1.000 & 1.000 & 0.843 & 0.587 \\
\hline RtoS & Increasing & Constant & Constant & Constant & Constant & Constant & Decreasing & Decreasing \\
\hline \multicolumn{9}{|c|}{ National Insurance Company Limited } \\
\hline Indicators & $2002-03$ & 2003-04 & 2004-05 & $2005-06$ & 2006-07 & 2007-08 & 2008-09 & 2009-10 \\
\hline TE & 0.981 & 1.000 & 1.000 & 1.000 & 1.000 & 1.000 & 1.000 & 0.785 \\
\hline PTE & 1.000 & 1.000 & 1.000 & 1.000 & 1.000 & 1.000 & 1.000 & 1.000 \\
\hline SE & 0.981 & 1.000 & 1.000 & 1.000 & 1.000 & 1.000 & 1.000 & 0.785 \\
\hline RtoS & Constant & Constant & Constant & Constant & Constant & Constant & Constant & Decreasing \\
\hline
\end{tabular}


Am. J. Soc. Mgmt. Sci., 2011, 2(2): 237-247

Table 2 shows the year wise analysis of TE, PTE and SE

\begin{tabular}{|c|c|c|c|c|c|c|c|c|c|}
\hline \multicolumn{5}{|l|}{ 2002-03 } & \multicolumn{5}{|l|}{ 2003-04 } \\
\hline Company & TE & PTE & SE & RtoS & Company & TE & PTE & SE & RtoS \\
\hline Tata & 0.041 & 0.980 & 0.042 & Increasing & Tata & 0.057 & 0.89 & 0.063 & Increasing \\
\hline Iffco & 0.198 & 1.000 & 0.198 & Increasing & Iffco & 0.137 & 1.000 & 0.137 & Increasing \\
\hline Reliance & 0.029 & 0.980 & 0.030 & Increasing & Reliance & 0.300 & 1.000 & 0.300 & Increasing \\
\hline Royal & 0.033 & 0.866 & 0.038 & Increasing & Royal & 0.167 & 0.784 & 0.213 & Increasing \\
\hline Bajaj & 0.032 & 0.914 & 0.035 & Increasing & Bajaj & 0.258 & 0.928 & 0.278 & Increasing \\
\hline $\mathrm{ICICl}$ & 0.041 & 0.912 & 0.045 & Increasing & $\mathrm{ICICI}$ & 1.000 & 1.000 & 1.000 & Constant \\
\hline United & 0.939 & 1.000 & 0.939 & Increasing & United & 0.635 & 1.000 & 0.635 & Increasing \\
\hline Oriental & 0.595 & 1.000 & 0.595 & Increasing & Oriental & 0.550 & 1.000 & 0.550 & Increasing \\
\hline New India & 1.000 & 1.000 & 1.000 & Constant & New India & 1.000 & 1.000 & 1.000 & Constant \\
\hline National & 0.981 & 1.000 & 0.981 & Increasing & National & 1.000 & 1.000 & 1.000 & Constant \\
\hline \multicolumn{5}{|l|}{ 2004-05 } & \multicolumn{5}{|l|}{ 2005-06 } \\
\hline Company & TE & PTE & SE & RtoS & Company & TE & PTE & SE & RtoS \\
\hline Tata & 0.046 & 0.810 & 0.057 & Increasing & Tata & \begin{tabular}{|l|}
0.079 \\
\end{tabular} & 0.552 & 0.151 & Increasing \\
\hline Iffco & 0.161 & 1.000 & 0.161 & Increasing & Iffco & \begin{tabular}{|l|}
0.134 \\
\end{tabular} & 0.475 & 0.281 & Increasing \\
\hline Reliance & 0.283 & 1.000 & 0.283 & Increasing & Reliance & 0.241 & 1.000 & 0.241 & Increasing \\
\hline Royal & 0.124 & 0.782 & 0.159 & Increasing & Royal & \begin{tabular}{|l|}
0.205 \\
\end{tabular} & 0.746 & 0.275 & Increasing \\
\hline Bajaj & 0.191 & 0.932 & 0.205 & Increasing & Bajaj & \begin{tabular}{|l|}
0.244 \\
\end{tabular} & 0.965 & 0.253 & Increasing \\
\hline $\mathrm{ICICl}$ & 0.332 & 0.492 & 0.674 & Increasing & $\mathrm{ICICl}$ & 0.246 & 0.502 & 0.491 & Increasing \\
\hline United & 0.735 & 1.000 & 0.735 & Increasing & United & 0.811 & 1.000 & 0.811 & Increasing \\
\hline Oriental & 0.728 & 1.000 & 0.728 & Increasing & Oriental & \begin{tabular}{|l|}
0.872 \\
\end{tabular} & 1.000 & 0.872 & Increasing \\
\hline New India & 1.000 & 1.000 & 1.000 & Constant & New India & 1.000 & 1.000 & 1.000 & Constant \\
\hline National & 1.000 & 1.000 & 1.000 & Constant & National & 1.000 & 1.000 & 1.000 & Constant \\
\hline \multicolumn{5}{|l|}{ 2006-07 } & \multicolumn{5}{|l|}{ 2007-08 } \\
\hline Company & TE & PTE & SE & RtoS & Company & TE & PTE & SE & RtoS \\
\hline Tata & 0.445 & 0.963 & 0.462 & Increasing & Tata & \begin{tabular}{|l|}
0.413 \\
\end{tabular} & 1.000 & 0.413 & Increasing \\
\hline Iffco & 0.676 & 1.000 & 0.676 & Increasing & Iffco & \begin{tabular}{|l|}
0.247 \\
\end{tabular} & 0.517 & 0.478 & Increasing \\
\hline Reliance & 0.567 & 1.000 & 0.567 & Increasing & Reliance & \begin{tabular}{|l|}
0.617 \\
\end{tabular} & 1.000 & 0.617 & Increasing \\
\hline Royal & 0.352 & 0.734 & 0.480 & Increasing & Royal & \begin{tabular}{|l|}
0.275 \\
\end{tabular} & 0.647 & 0.425 & Increasing \\
\hline Bajaj & 1.000 & 1.000 & 1.000 & Constant & Bajaj & 1.000 & 1.000 & 1.000 & Constant \\
\hline $\mathrm{ICICl}$ & 0.492 & 0.501 & 0.982 & Decreasing & $\mathrm{ICICl}$ & \begin{tabular}{|l|}
0.255 \\
\end{tabular} & 0.323 & 0.788 & Increasing \\
\hline United & 0.676 & 0.777 & 0.870 & Increasing & United & \begin{tabular}{|l|}
0.061 \\
\end{tabular} & 0.667 & 0.092 & Increasing \\
\hline Oriental & 0.988 & 1.000 & 0.988 & Increasing & Oriental & \begin{tabular}{|l|}
0.835 \\
\end{tabular} & 1.000 & 0.835 & Increasing \\
\hline New India & 1.000 & 1.000 & 1.000 & Constant & New India & 1.000 & 1.000 & 1.000 & Constant \\
\hline National & 1.000 & 1.000 & 1.000 & Constant & National & 1.000 & 1.000 & 1.000 & Constant \\
\hline \multicolumn{5}{|l|}{ 2008-09 } & \multicolumn{5}{|l|}{ 2009-10 } \\
\hline Company & TE & PTE & SE & RtoS & Company & TE & PTE & SE & RtoS \\
\hline Tata & 0.849 & 1.000 & 0.849 & Increasing & Tata & \begin{tabular}{|l|}
0.728 \\
\end{tabular} & 1.000 & 0.728 & Increasing \\
\hline Iffco & 0.513 & 0.867 & 0.592 & Increasing & Iffco & 1.000 & 1.000 & 1.000 & Constant \\
\hline Reliance & 1.000 & 1.000 & 1.000 & Constant & Reliance & 1.000 & 1.000 & 1.000 & Constant \\
\hline Royal & 0.450 & 0.926 & 0.486 & Increasing & Royal & 0.413 & 0.612 & 0.675 & Increasing \\
\hline Bajaj & 0.775 & 1.000 & 0.775 & Increasing & Bajaj & \begin{tabular}{|l|}
0.702 \\
\end{tabular} & 0.751 & 0.934 & Decreasing \\
\hline $\mathrm{ICICl}$ & 0.631 & 0.847 & 0.744 & Decreasing & $\mathrm{ICICl}$ & \begin{tabular}{|l|}
0.814 \\
\end{tabular} & 1.000 & 0.814 & Decreasing \\
\hline United & 0.755 & 0.796 & 0.948 & Decreasing & United & \begin{tabular}{|l|}
0.563 \\
\end{tabular} & 0.912 & 0.618 & Decreasing \\
\hline Oriental & 1.000 & 1.000 & 1.000 & Constant & Oriental & \begin{tabular}{|l|}
0.711 \\
\end{tabular} & 1.000 & 0.711 & Decreasing \\
\hline New India & 0.843 & 1.000 & 0.843 & Decreasing & New India & \begin{tabular}{|l|}
0.587 \\
\end{tabular} & 1.000 & 0.587 & Decreasing \\
\hline National & 1.000 & 1.000 & 1.000 & Constant & National & \begin{tabular}{|l|}
0.785 \\
\end{tabular} & 1.000 & 0.785 & Decreasing \\
\hline
\end{tabular}

B. Year wise analysis: This has been done to find out the year wise efficiencies of various companies under consideration i.e. the effort has been made to find out the year in which the maximum numbers of companies lie on the frontier with efficiency score equal to 1 or no one company lie on the frontier.

In almost all the year one or two public sector companies was found on the frontier. But gradually this is vanishing as shown in the table 2 that in the 
year 2009-10 not even a single public sector company lie on the frontier due to its technical efficiency scores less than 1 . This can be attributable to the fact that companies are operating on decreasing to scale and their position is taken by private sector general insurance companies as only private sector insurance companies lie on the frontier with efficiency scores equal to 1 .

II. Analysis of Mean of Technical, Pure Technical and Scale Efficiency: The analysis of mean of TE, PTE and SE has done by two ways: A. Sector wise analysis; B. Overall analysis.

A. Sector wise analysis: According to the background of the insurers in India it can be separated in two groups: 1) Public Sector Insurers; 2) Private Sector Insurers. In the sector wise analysis efforts has been made to evaluate the mean of technical efficiency, pure technical efficiency and scale efficiency of public sector as well as of private sector for the period under consideration.

Table 3 shows the sector wise analysis of mean of TE, PTE and SE

\begin{tabular}{|l|l|l|l|l|}
\hline Year & Sector & $\begin{array}{l}\text { Mean of } \\
\text { TE }\end{array}$ & $\begin{array}{l}\text { Mean of } \\
\text { PTE }\end{array}$ & $\begin{array}{l}\text { Mean of } \\
\text { SE }\end{array}$ \\
\hline \multirow{2}{*}{$2002-03$} & Private & 0.062 & 0.942 & 0.064 \\
\cline { 2 - 5 } & Public & 0.878 & 1.000 & 0.878 \\
\hline $2003-04$ & Private & 0.319 & 0.933 & 0.331 \\
\cline { 2 - 5 } & Public & 0.796 & 1.000 & 0.796 \\
\hline $2004-05$ & Private & 0.189 & 0.836 & 0.256 \\
\cline { 2 - 5 } & Public & 0.865 & 1.000 & 0.865 \\
\hline $2005-06$ & Private & 0.191 & 0.736 & 0.282 \\
\cline { 2 - 5 } & Public & 0.920 & 1.000 & 0.920 \\
\hline \multirow{2}{*}{$2006-07$} & Private & 0.588 & 0.866 & 0.694 \\
\cline { 2 - 5 } & Public & 0.916 & 0.944 & 0.964 \\
\hline $2007-08$ & Private & 0.467 & 0.747 & 0.620 \\
\cline { 2 - 5 } & Public & 0.724 & 0.916 & 0.731 \\
\hline $2008-09$ & Private & 0.703 & 0.940 & 0.741 \\
\cline { 2 - 5 } & Public & 0.899 & 1.000 & 0.947 \\
\hline $2009-10$ & Private & 0.776 & 0.893 & 0.858 \\
\cline { 2 - 5 } & Public & 0.661 & 0.978 & 0.675 \\
\hline
\end{tabular}

he mean of TE of private sector insurance companies has shown increasing trends over a period of time as it was 0.062 in the year 2002-03 which increased to 0.776 in the year 2009-10 except the year 2007-08 in which there is slightly decrease in the mean of TE, which might be attributable to change in the economies of scale. As far as the mean of TE of Public sector insurance companies is concerned it was not reinforced throughout the study period i.e. it followed the diverse trend over a period of time. Numerically it is stated as $0.878,0.796,0.865,0.920$, $0.916,0.724,0.899$ and 0.661 . If we look at the two point of time of the study, then it will show the decrease in mean of TE of public sector. The reason can be attributable to the existence of PTE inefficiency and Scale inefficiency.

The mean of PTE of both the private as well as public sector insurance companies has shown the diverse trends over a period of time as it is shown in the table III. The mean of PTE of private sector was 0.942 in the year 2002-03 which decrease to 0.893 in the year 2009-10. As far as the mean of PTE of public sector is concerned it remains static for first 4 year of the study period and thereafter it shows diverse trends year after year. But if we look at two point of time then it will show that mean of PTE has decreased as it was 1.000 in the year 2002-03 which decreased to 0.978 in the year 2009-10.

The mean of scale efficiencies of private and public sector is reverse to each other. The mean of scale efficiency of private sector has increased over a period of time as shown in the table 3 as it was 0.064 in the year 2002-03 which increased to 0.858 in the year 2009-10. On the other hand the mean of scale efficiency of public sector is decreasing over a period of time as it was 0.878 in the year 2002-03 which decreased to 0.675 in the year 2009-10. The reason might be attributable to the fact that private sector taking the much advantages of scale efficiencies which results in more technical efficiency for the private sector.

B. Overall analysis: As against the sector wise analysis, the overall analysis of mean of TE, PTE and SE was made to know the year in which the mean technical efficiency, pure technical efficiency and scale efficiency of all the insurers were highest as against the period of study under consideration.

Table 4 shows the overall analysis of mean of TE, PTE and SE

\begin{tabular}{|l|l|l|l|l|}
\hline Year & & $\begin{array}{l}\text { Mean of } \\
\text { TE }\end{array}$ & Mean PTE & $\begin{array}{l}\text { Mean } \\
\text { of SE }\end{array}$ \\
\hline $2002-03$ & $\begin{array}{l}\text { All } \\
\text { Insurers }\end{array}$ & 0.389 & 0.965 & 0.390 \\
\hline $2003-04$ & $\begin{array}{l}\text { All } \\
\text { Insurers }\end{array}$ & 0.510 & 0.961 & 0.518 \\
\hline $2004-05$ & $\begin{array}{l}\text { All } \\
\text { Insurers }\end{array}$ & 0.460 & 0.902 & 0.500 \\
\hline $2005-06$ & $\begin{array}{l}\text { All } \\
\text { Insurers }\end{array}$ & 0.483 & 0.821 & 0.537 \\
\hline $2006-07$ & $\begin{array}{l}\text { All } \\
\text { Insurers }\end{array}$ & 0.720 & 0.898 & 0.803 \\
\hline $2007-08$ & $\begin{array}{l}\text { All } \\
\text { Insurers }\end{array}$ & 0.570 & 0.815 & 0.665 \\
\hline $2008-09$ & $\begin{array}{l}\text { All } \\
\text { Insurers }\end{array}$ & 0.782 & 0.944 & 0.824 \\
\hline $2009-10$ & $\begin{array}{l}\text { All } \\
\text { Insurers }\end{array}$ & 0.730 & 0.927 & 0.785 \\
\hline
\end{tabular}


The table 4 shows that there is increasing trend in mean technical efficiency, which can be attributable to increase in PTE and SE. For the purpose of overall analysis we have classified the mean efficiency scores into 0- 0.3, 0.3-0.6, 0.6-0.9 and 0.9-1 and thereafter the comparison of all the insurers have been made with respect to their efficiency scores in order to find out the range within which they lie. By following the same we found that only in the year 2002-03 all insurers fall in the first category. Thereafter in all the year it was found in the higher interval of 0.3-0.6 and 0.6-0.9. This might be because of all the insurers are operating on increasing return to scale or it can be contributed by PTE and SE. Moreover it has shown in table 4 that the mean of TE increased from 0.389 in the year 2002-03 to 0.730 in the 2009-10. By comparing it was found that all the insurers are also better at PTE, as that mean of PTE is more as compared with mean of TE in all the year. But this is also vanishing if we make the comparison of mean of PTE of the year 2002-03 which was 0.965 with the mean of PTE of the year 2009-10 which was 0.927 . This can be justified through scale economies, as most of the health insurers have strong increasing return to scale and also taking the advantages from the scale economies as it has increased from 0.390 in the year 2002-03 to 0.785 in the year 2009-10.

\section{Analysis of Improvement Direction and Improvement Space for Health Insurers}

On the basis of technical efficiency scores of various companies for the period under consideration, the improvement direction and improvement space are derived. It signifies the percentage of technical efficiency scores which require for them to be on the frontier i.e. the additional scores needed to be on the frontier.

Table 5 shows improvement direction and improvement space

\begin{tabular}{|l|l|l|l|l|l|l|l|l|}
\hline & $\mathbf{2 0 0 2 - 0 3}$ & $\mathbf{2 0 0 3 - 0 4}$ & $\mathbf{2 0 0 4 - 0 5}$ & $\mathbf{2 0 0 5 - 0 6}$ & $\mathbf{2 0 0 6 - 0 7}$ & $\mathbf{2 0 0 7 - 0 8}$ & $\mathbf{2 0 0 8 - 0 9}$ & $\mathbf{2 0 0 9 - 1 0}$ \\
\hline Tata & $95.9 \%$ & $94.3 \%$ & $95.4 \%$ & $92.1 \%$ & $55.5 \%$ & $58.7 \%$ & $15.11 \%$ & $27.21 \%$ \\
\hline Iffco & $80.2 \%$ & $86.3 \%$ & $83.9 \%$ & $86.6 \%$ & $32.4 \%$ & $75.3 \%$ & $48.7 \%$ & $0 \%$ \\
\hline Reliance & $97.1 \%$ & $70 \%$ & $71.7 \%$ & $75.9 \%$ & $43.3 \%$ & $38.3 \%$ & $0 \%$ & $0 \%$ \\
\hline Royal & $96.7 \%$ & $83.3 \%$ & $87.6 \%$ & $79.5 \%$ & $64.8 \%$ & $72.5 \%$ & $55 \%$ & $58.7 \%$ \\
\hline Bajaj & $96.8 \%$ & $74.2 \%$ & $80.9 \%$ & $75.6 \%$ & $0 \%$ & $0 \%$ & $22.5 \%$ & $29.8 \%$ \\
\hline ICICI & $95.9 \%$ & $0 \%$ & $66.8 \%$ & $75.4 \%$ & $50.8 \%$ & $74.5 \%$ & $36.9 \%$ & $18.6 \%$ \\
\hline United & $6.1 \%$ & $36.5 \%$ & $26.5 \%$ & $18.9 \%$ & $32.4 \%$ & $93.9 \%$ & $24.5 \%$ & $43.7 \%$ \\
\hline Oriental & $40.5 \%$ & $45 \%$ & $27.2 \%$ & $12.8 \%$ & $1.2 \%$ & $16.5 \%$ & $0 \%$ & $28.9 \%$ \\
\hline New India & $0 \%$ & $0 \%$ & $0 \%$ & $0 \%$ & $0 \%$ & $0 \%$ & $15.7 \%$ & $41.3 \%$ \\
\hline National & $1.9 \%$ & $0 \%$ & $0 \%$ & $0 \%$ & $0 \%$ & $0 \%$ & $0 \%$ \\
\hline
\end{tabular}

The table 5 shows that there are diverse trends of improvement direction and improvement space over a period of time. For all the private sector health insurers, the improvement space is decreasing, which is good sign for the private sector as it signifies that their distance from the frontier is becoming narrow and they are directing toward frontier. As stated numerically, initially the improvement space was $95.9 \%, 80.2 \%, 97.1 \%, 96.7 \%, 96.8 \%$ and $95.9 \%$ in the year 2002-03 for Tata AIG, Iffco, Reliance, Royal, Bajaj and $\mathrm{ICICl}$ which decreased to $27.21 \%$, $0 \%, 0 \%, 59.7 \%, 29.8 \%$ and $18.6 \%$ in the year 2009 10. This shows that companies in the private sector are expanding their activities as well as outreach in order to survive and grow in the competitive market and consequently these are finding place on the frontier or coming near to frontier.
As far as the public sector companies are concerned all are showing reverse improvement space and direction except Oriental Insurance Company Limited. The reason behind this lies in the fact that these are going out of the frontier as shown in the table that initially the improvement space was $6.1 \%$, $0 \%$ and $1.9 \%$, which increases over a time and become $43.7 \%, 41.3 \%$ and $21.5 \%$. This shows that although the public sector companies was on or near the frontier, yet gradually this sector is underperforming and their position is slowly and steadily taken over by the privates sector companies. 


\section{CONCLUSION:}

In this study DEA framework has been applied for the evaluation of efficiencies of health insurance business of general insurance companies in India. It was observed that overall general insurers carrying health insurance business at an average technical efficiency of $73 \%$, pure technical efficiency of $92 \%$ and scale efficiency of $78 \%$. On the other hand sector wise performance analysis has indicated that technical efficiency of the private companies is $77 \%$ which is $10 \%$ more than that of public sector Companies. This can attributable to the fact that private sector companies are operating on increasing return to scale and taking the advantages of pure technical efficiency and scale efficiency. While public sector companies are becoming mature, started operating on decreasing return to scale and due to competition gradually the position of public sector companies is taken over by private sector companies as it is shown in the study that improvement space and direction of private sector is showing positive sign as these are moving toward frontier, which is reverse in the case of public sector companies.

\section{REFERENCES}

Brockett, P.L., Cooper, W.W., Golden, L.L., Rousseau, J.J and Wang, $Y$ (1998). DEA evaluations of the efficiency of organizational forms and distribution systems in the US property and liability insurance. International Journal of System Science, 29(11): 1235-1247.

Boonyasai, T., Grace, M.F and Skipper, H.D (2002). The Effect of Liberalization and Deregulation on Life Insurer Efficiency. Center for Risk Management and Insurance Research, Working Paper No. 02-2.

http://rmictr.gsu.edu/Papers/WP02-2.pdf

Bikker, J.A. and Leuvensteijn, M.V (2008). Competition and Efficiency in the Dutch Life Insurance Industry. Journal of Applied Economics, 40: 2063-2084.

Cummins, J.D and Zi, H (1998). Measuring Cost Efficiency in the U.S. Life Insurance Industry: Econometric and Mathematical Programming Approaches. Journal of productivity analysis, 10:131-152.

Cummins, J.D., Turchetti, G and Weiss, M.A (1996). Productivity and technical efficiency of Italian insurance Industry. Technical report, The Wharton School, University of Pennsylvania.

Coelli, T.J (1996). Centre for Efficiency and Productivity Analysis (CEPA). Working Paper No.8.
Charnes, A., Cooper, W.W and Rhodes, E (1978). Measuring the efficiency of decision making units. European Journal of Operation Research, 2: 429-444.

Cummins, J.D and Misas, M.R (2001). Deregulation, Consolidation and Efficiency: Evidence From the Spanish Insurance Industry. Working Paper No.02-01. http://papers.ssrn.com/sol3/papers.cfm?abstract_id=29 4687

Cummins, J.D., Weiss, M.A and Zi, H (2003). Economies of Scope in Financial Services: A DEA Bootstrapping Analysis of the US Insurance Industry. http://sshuebner.org/documents/DEAScope0903b.pdf

Chang, C.P (2006). Establishing a Performance Prediction Model for Insurance Companies. The Journal of American Academy of Business, Cambridge, 8(1): 7377.

Doherty, N. A., 1981, "The Measurement of Output and Economies of Scale in Property Liability Insurance," Journal of Risk and Insurance 48: 391-402.

Debreu, G. (1951). The Coefficient of Resource Utilization. Econometrica, 19(3): 273-292

Eling, $M$ and Luhnen, $M$ (2008). Frontier Efficiency Methodologies to Measure Performance in the Insurance Industry. Working paper on Risk Management and Insurance no.56. http://papers.ssrn.com/sol3/papers.cfm?abstract_id $=12$ $37662 \&$ rec $=1 \&$ srcabs $=1354108$.

Eling, $M$ and Luhnen, $M$ (2010). Frontier Efficiency Methodologies to Measure Performance in the Insurance Industry: Overview, Systematization and Recent Developments. The International Association for the Study of Insurance Economics, The Geneva Paper, 35: 217-265.

Fields, J.A and Murphy, N.B (1989). An Analysis of Efficiency in the Delivery of Financial Services: The Case of Life Insurance Agencies. Journal of Financial Services Research, 2: 343-356.

Farrell, M.J (1957). The Measurement of Productive Efficiency. Journal of Royal Statistical Society. Series A (General), 120(3): 253-290.

Fukuyama, H (1997). Investigating productive efficiency and productive changes of Japanese life insurance companies. Pacific-Basin Finance Journal, 5: 481-509.

Grace, M. F., and Timme, S. G. (1992). An Examination of Cost Economie $s$ in the United States Life Insurance Industry. Journal of Risk and Insurance, 59, 72-103. 
Gardner, L.A. and Grace, M.F (1993). X-Efficiency in the US Life Insurance Industry. Journal of Banking and Finance, 17: 497-510.

Houston, J. and Simon, R (1970). Economies of Scale in Financial Institutions: A Study of Life Assurance. Econometrica, 38(6): 856-864.

Korhonen, P (1997). Searching the Efficient Frontier in Data Envelopment Analysis. International Institute for Applied Systems Analysis, Interim Report -9779.http://www.iiasa.ac.at/Admin/PUB/Documents/IR97-079.pdf

$\mathrm{Li}, \quad \mathrm{K}$ (2005). The Empirical Analysis of Chinese Life Insurance Companies. Insurance Research (China), 2 : 13-17.

Martin, E (2003). An Application of Data Envelopment Analysis Methodology in the Performance Assessment of Zaragoza University Departments. http://www.dteconz.unizar.es/DT2003-06.pdf

Owusu-Ansah, E., Dontwi, I. K., Seidu, B., Abudulai, G. and Sebil, C (2010). Technical Efficiencies of Ghanaian General Insurers. American Journal of Social and Management Science, 1(1): 75-87.
Praetz, P (1980). Returns to Scale in US Life Insurance Industry. Journal of Risk and Insurance,47: 525-533.

Qiu, S and Chen, B. (2006). Efficiencies of Life Insurers in China An Application of Data Envelopment Analysis.

http://www.ccfr.org.cn/cicf2006/cicf2006paper/2006013003 3345.pdf

Rai, A (1996). Cost Efficiency of International Insurance Firms. Journal of Financial Services Research, 10: 213-233.

Sherman, H.D (1981). Measurement of Relative Efficiency of Health Service Organization With Data Envelopment Analysis-A Simulation. Working paper no 1200-81.

Weiss, M.A (1986). Analysis of Productivity at the Firm Level: An Application to Life Insurers. The Journal of Risk and Insurance, 53(1): 49-84.

Yuengert, A.M (1993). The Measurement of Efficiency in Life Insurance: Estimates of a Mixed Normal-Gamma Error Model. Journal of Banking and Finance, 17: 483496.

Yaun, Y and Phillips, R.D. (2008). Financial Integration and Scope Efficiency in U.S Financial Services Post Gramm-Leach-Bliley. http://fic.wharton.upenn.edu/fic/papers/08/0832.pdf 